\title{
Detection of Trace Amounts of Selenium Ions in Water and Blood Samples by Solid Phase Extraction Using Thiolated Nanosilica
}

\author{
Fereshteh Keyghobadi (MSc) \\ Department of Analytical Chemistry, \\ Golestan University of Medical \\ Sciences, Gorgan, Iran \\ Nader Bahramifar $(\mathbf{P h D})$ \\ Department of Analytical Chemistry, \\ Tarbiat Modares University, Noor, Iran \\ Elahe Gharekhani (MSc) \\ Department of Toxicology, Golestan \\ University of Medical Sciences, \\ Gorgan, Iran \\ Seyyedeh Marzieh Kia (MSc) \\ Department of Food Sciences, \\ Golestan University of Medical \\ Sciences, Gorgan, Iran \\ Corresponding author: Fereshteh \\ keyghobadi \\ Email: \\ fereshteh_keyghobadi@yahoo.com \\ Tel: +98-9119668393 \\ Address: Golestan University of \\ Medical Sciences, Gorgan, Iran \\ Received: 31 Oct 2018 \\ Revised: 05 Jan2019 \\ Accepted: 13 Jan 2019

\section{(c) (i) (8)} \\ This work is licensed under a Creative \\ Commons Attribution 4.0 License.
}

\begin{abstract}
Background and Objectives: In this study, nanosilica modified with $\mathrm{HS}-\mathrm{Si}_{2}$ thiol groups was utilized as adsorbent for solid phase extraction, as a fast and reliable method of preconcentration and separation of very small quantities of selenium ions from water and blood samples.

Methods: The samples included four natural water samples and one biological sample (blood serum) prepared in volumes of 25, 100, 200, 300, 400 and $500 \mathrm{ml}$. The samples were analyzed by solid phase microextraction, using thiolated-nanosilica (as adsorbent), ultraviolet-visible spectrophotometry and atomic absorption spectroscopy.

Results: 0ptimized conditions for preconcentration of a $25 \mathrm{ml} 0.2 \mathrm{mg} / \mathrm{l}$ selenium solution were pH 5, $40 \mathrm{mg}$ of adsorbent, sample-adsorbent mixing time of 15 minutes and 5 $\mathrm{ml}$ of $2 \mathrm{~N}$ sulfuric acid as detergent. The volume limit and concentration factor were 400 and 80, respectively. Limit of detection and relative standard deviation of the method were 0.46 $\mu \mathrm{g} / \mathrm{l}$ and $0.9 \%$, respectively.

Conclusion: This study is the first to successfully utilize thiolated nanosilica for measuring low selenium levels. Thiolation of the absorbent increases selenium adsorption by thiolated-silica compared to $\mathrm{Si}_{2}$.

Keywords: Solid phase extraction, Selenium, Preconcentration, Nano, IV-visible spectrophotometry.
\end{abstract}

This paper should be cited as: Keyghobadi F, Bahramifar N, Gharekhani E, Kia SM[Detection of Trace Amounts of Selenium Ions in Water and Blood Samples by Solid Phase Extraction Using Thiolated Nanosilica]. mljgoums. 2019; 13(5): 32-37 


\section{INTRODUCTION}

Selenium is a trace element essential for human health. Nowadays, selenium supplementation is approved as part of the public health policies in selenium-deficient regions $(1,2)$. Reduced selenium levels in the body weaken the immune system and results in the formation of toxic substances in the blood and vulnerability of humans to various diseases. The main sources of selenium in the environment are industrial resources for agricultural practices. The tendency of this element to bioaccumulate at base of the food chain, from sediment to marine plants and then to animals, has raised some concerns (3). The maximum safe dietary selenium intake is about $800 \mu \mathrm{g} /$ day, while daily intake of $400 \mu \mathrm{g}$ selenium prevents poisoning and regulates the amount of nutrients (4). Due to the importance of this element, various methods such as solid phase microextraction have been proposed for its measurement (5). The aforementioned method uses different adsorbents as a stationary phase. In recent years, scientists have focused on the use of nanomaterial-based adsorbents for preconcentration and separation of metal ions. These materials have compelling characteristics including large surface area to volume ratio and large number of active analyte adsorption sites. Thus, nanomaterials can selectively adsorb metal ions due to the presence of suitable surface functional groups. Similar to nanomaterials including $\mathrm{SiO}_{2}, \mathrm{Al}_{2} \mathrm{O}_{3}, \mathrm{TiO}_{2}, \mathrm{ZrO}_{2}$ and $\mathrm{CeO}_{2}$, metal oxides show a good level of surface activity. In addition, adsorbent preparation is very simple and inexpensive compared to other commonly used solid metals. Functionalization of silica nanoparticles with various suitable reagents can notably improve the adsorbent-analyte interactions by increasing both sensitivity and selectivity. Mofidi et al. used thiolated mesoporous mcm41 as a new adsorbent for preconcentration of mercury using solid phase extraction and spectrophotometric determination. In this study, we used thiolated nanosilica adsorbents as stationary phase in solid phase extraction, for separation and preconcentration of low selenium levels from biological and water samples. We aimed to increase selenium adsorption capacity from these samples by functionalizing carbon nanotubes with thiol groups. The most important reasons for the use of thiolated nanosilica adsorbents are large surface area, selectivity, high adsorption capacity, stability and reusability.

\section{MATERIAL AND METHODS}

We used 3-mercaptopropyl trimethoxysilane to prepare nanosilica. To remove organic impurities, $1 \mathrm{~g}$ of $\mathrm{SiO}_{2}$ nanoparticles was added to $40 \mathrm{ml}$ of toluene, and the solution was refluxed for 24 hours at 80-90 ${ }^{\circ} \mathrm{C}$. After centrifugation at room temperature, supernatant was discarded and 40 $\mathrm{ml}$ of toluene was added two times to the sediment. The mixture was refluxed at $80-90$ ${ }^{\circ} \mathrm{C}$ for 24 hours and then filtered through Whatman filter papers (grade 42). The solid matter was dried at room temperature after washing with $20 \mathrm{ml}$ of toluene several times.

One $\mathrm{g}$ of prepared nanosilica powder was added to $40 \mathrm{ml}$ of toluene and $2 \mathrm{~g}$ of reagent (3-[Methoxy(dimethyl)silyl]-1-propanethiol).

The solution was refluxed for 24 hours at 80$90^{\circ} \mathrm{C}$. After reaching room temperature, the solution was filtered using Whatman filter papers (grade 42). After washing with $20 \mathrm{ml}$ of toluene and drying at room temperature, the solid matter was used as the solid phase in the solid phase extraction method.

Functional groups created at the surface of carbon nanotubes were identified using $\mathrm{KBr}$ tablets and Fourier transform infrared spectroscopy (Shimadzu FT-IR 8400, Japan) (Figure 1). The vario EL elemental analyzer (Germany) was used for quantitative analysis of the elements in the crude and thiolated carbon nanotubes.

Experiments were performed in a discontinuous system with thiolated nanosilica adsorbents. The amount of adsorbent, contact time, impact of acid detergent concentration and $\mathrm{pH}$ were investigated. The effect of these parameters was studied by keeping all parameters constant except for one. To measure selenium in natural water samples, various parameters affecting the extraction efficiency was optimized using different prepared solutions of selenium. Parameters including $\mathrm{pH}$, amount of adsorbent, time required for mixing of adsorbent and specimen, concentration and volume of sulfuric acid, the limit volume, limit of detection (LOD) and precision of the method were investigated to determine optimal conditions for evaluating the efficiency of the proposed pre-concentration method. Selenium 
ion measurement was carried out in water samples using nitric acid. Then, $100 \mathrm{ml}$ of each sample (after regulating $\mathrm{pH}$ ) was passed through the cartridge using a vacuum pump. After washing with $2 \mathrm{~N}$ sulfuric acid, $1 \mathrm{M}$ HCL, $2 \% \mathrm{KL}$ and $1 \%$ stained starch adhesive solution were used. Adsorption of each solution was read using UV-visible spectrophotometry.

Blood samples were slowly transferred to tubes prewashed with acid and then capped. After being transferred to the laboratory, the tubes were centrifuged at 1500 RPM for 10-15 minutes. Serum was separated using a Pasteur pipette and poured into another sterile tube. A $10 \%$ (v:v) serum solution was prepared using deionized water (6). Then, $20 \mathrm{ml}$ of the $\mathrm{pH}$ adjusted diluted specimen were mixed with the adsorbent and passed through the cartridge and later washed with $2 \mathrm{~N}$ sulfuric acid. The washing solution was stained with $1 \mathrm{M} \mathrm{HCL}$, $2 \% \mathrm{Kl}$ and $1 \%$ starch solution, and the adsorption of selenium ions in the solution was measured by a UV-visible spectrophotometer.
Selenium was measured in serum samples based on a specific method and using a furnace atomic absorption spectrophotometer. Effect of different $\mathrm{pH}$ levels (3-7) was investigated. The contact time (5,10 and 15 minutes) and time of adsorbent mixing (20 minutes) were determined. The amount of adsorbent $(10,20$, 30,40 and $50 \mathrm{mg}$ ) was determined. The effect of different concentrations $(0.2,0.5,1,1.5,2$ and $3 \mathrm{~N}$ ) of detergent was also investigated.

Adsorption of selenium ion was carried out using thiolated nanosilica. The concentration of aqueous solutions was measured using a Shimadzu UV- 160PC spectrophotometer. Selenium standard stock solution (1000 $\mathrm{mg} / \mathrm{ml}$ ) was used to prepare standard solutions containing selenium ion $(0.2,0.4,0.6,0.8,1$ and $1.2 \mathrm{mg} / \mathrm{ml})$.

Under optimal conditions, the solid phase extraction process was performed for preconcentration of the standard solutions. Finally, absorption of each solution was determined by a UV-spectrophotometer (Figure 1).

Figure 1- Calibration curve for spectrophotometric measurement of selenium

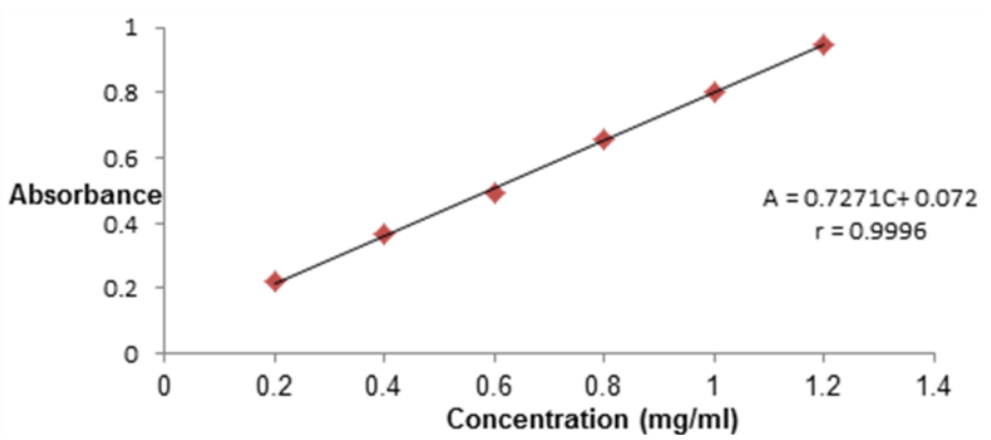

Figure 2- IR spectrum of the nanosilica ( $\mathrm{Si}$ ) and thiolated nanosilica (HS-Si) absorbent

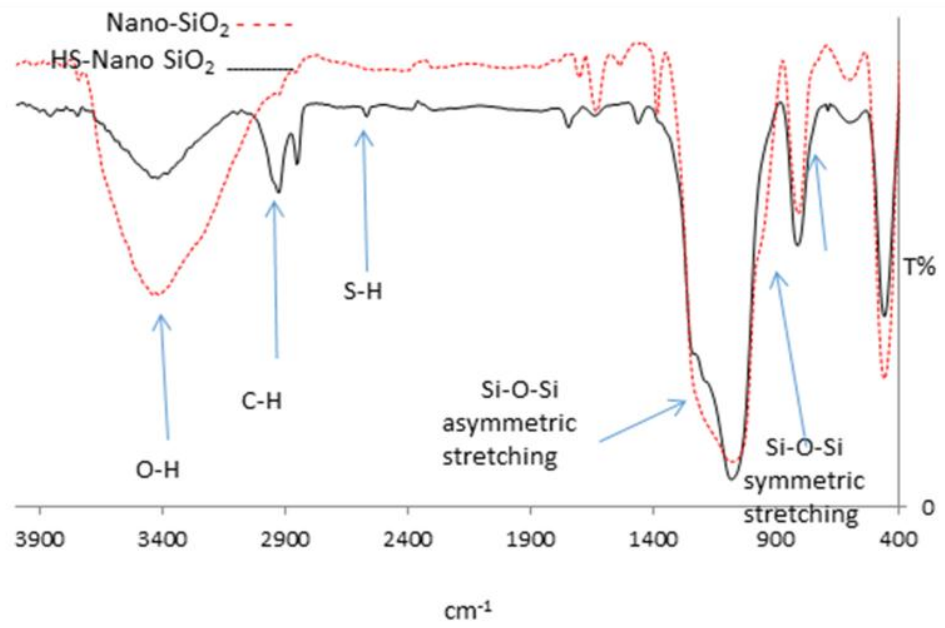




\section{RESULTS}

\section{carbon nanotubes}

The structural properties of thiolated

Figure 2 shows the results of FTIR analysis for the crude absorbent and the thiolated nanosilica.

As shown in figure 2, a C-S stretching band at $1686 \mathrm{~cm}^{-1}$ is visible for the spectrum of thiolated adsorbent, which was absent in the $\mathrm{Si}$ spectrum. The sharp absorption peaks at 1093 $\mathrm{cm}^{-1}$ and $810 \mathrm{~cm}^{-1}$ were related to the symmetric and asymmetric Si-O-Si stretching vibrations, respectively. In addition, the Si-OSi bending vibrations at $460 \mathrm{~cm}^{-1}$ is visible in both spectra (7). There was a visible but weak peak related to the $\mathrm{SH}$ stretching vibrations in the $2569 \mathrm{~cm}-1$ region of the SH-Si spectrum, which indicates the bonding of the thiol group to the nanosilica. The bands at $2854 \mathrm{~cm}^{-1}$ and $2923 \mathrm{~cm}^{-1}$ were related to symmetric and asymmetric $\mathrm{C}-\mathrm{H}$ stretching, respectively, which are increased in the SH-Si spectrum (7). Moreover, the broad band observed at 3440 $\mathrm{cm}-1$ was related to surface silanol groups and water molecules, which are reduced in the $\mathrm{SH}-$ $\mathrm{Si}$ because of the replacement of $\mathrm{SH}$ group with $\mathrm{OH}(8)$.

Effect of the solution's $p H$ on selenium adsorption by thiolated nanosilica

One of the factors affecting the solid phase extraction is $\mathrm{pH}$, which affects the quantitative inhibition of analytes on the stationary phase and the chemical properties of the adsorbent and metal ions, highlighting the utmost importance of optimization. Table 1 shows the results obtained for the effect of $\mathrm{pH}$. Effect of adsorbent level on the pattern of selenium adsorption by thiolated nanosilica

The amount of adsorbent is another important factor affecting the inhibition of metal cations and the pre-concentration process. The optimal amount of adsorbent was determined to be 40 $\mathrm{mg}$, which produced higher adsorption capacity and metal ion removal rate. Table 1 shows the effect of adsorbent level on selenium recovery.

Effect of contact time of analyte with solid phase on the adsorption of selenium by thiolated nanosilica

Contact time is an important factor for the proper use of an adsorbent in applied fields and indicates the rate of adsorption. The results showed that selenium is quickly adsorbed, so that $90 \%$ of adsorption equilibrium was achieved within 20 minutes. The favorable recovery of analytes depends on the duration of contact with the solid phase and requires a brief ion preconcentration period (10). Table 1 shows the effect of contact time of analyte with solid phase on the adsorption of selenium.

Effect of type and amount of detergent on selenium adsorption by thiolated nanosilica As shown in Table 1, the selenium recovery percentage was highest when using $\mathrm{H}_{2} \mathrm{SO}_{4}$ as detergent.

Table 1- Effect of the solution's parameters on selenium adsorption by thiolated nanosilica

\begin{tabular}{|c|c|c|}
\hline Optimization factor & Amount & Recovery percentage \\
\hline pH & $\begin{array}{l}3 \\
4 \\
5 \\
6 \\
7\end{array}$ & $\begin{array}{c}34.5 \\
94 \\
100 \\
96 \\
51\end{array}$ \\
\hline Type of detergent & $\begin{array}{c}\mathrm{HNO}_{3} \\
\mathrm{HCL} \\
\mathrm{H}_{3} \mathrm{PO}_{4}\end{array}$ & $\begin{array}{c}27 \\
41 \\
100\end{array}$ \\
\hline Amount of detergent (ppm) & $\begin{array}{l}10 \\
20 \\
30 \\
40 \\
50\end{array}$ & $\begin{array}{c}81 \\
84 \\
98 \\
105 \\
103\end{array}$ \\
\hline $\begin{array}{l}\text { Contact time of analyte with } \\
\text { the solid phase (minutes) }\end{array}$ & $\begin{array}{c}5 \\
10 \\
15 \\
20\end{array}$ & $\begin{array}{l}90 \\
97 \\
99 \\
98\end{array}$ \\
\hline Amount of adsorbent (mg) & $\begin{array}{c}0.1 \\
0.25 \\
0.5 \\
0.75 \\
1 \\
1.5\end{array}$ & $\begin{array}{c}0.1 \\
0.25 \\
0.5 \\
0.75 \\
1 \\
1.5\end{array}$ \\
\hline
\end{tabular}


Effect of detergent concentration on adsorption of selenium by thiolated nanosilica The acidic solution was chosen as the optimal washing solvent. The results of selenium washing with $0.2,0.5,1,2$, and 3 normal sulfuric acid solutions are shown in Table 1.

LOD is defined as the lowest concentration of analyte that can be measured at a specified level of confidence (11).

To determine the LOD, 10 blank samples (without selenium) were prepared and extracted based on the method explained previously, and the absorption of each solution was determined by UV-spectrophotometry.
The LOD of selenium for the device and method was calculated as $36.8 \mu \mathrm{g} / \mathrm{l}$ and 0.46 $\mu \mathrm{g} / \mathrm{l} \quad$ using $\quad \mathrm{LOD}=3 \sigma \mathrm{B} / \mathrm{m}$ and $\mathrm{LODa}=3 \sigma \mathrm{B} / \mathrm{m} . \mathrm{EF}$, respectively $(\sigma$ : standard deviation of absorption signal for control solution, $\mathrm{m}$ : slope, EF: preconcentration factor).

Accuracy of the method is in fact a measure of its repeatability. Relative standard deviation $(R S D)$ was used to measure accuracy of the analytical method for 10 samples taken from the preconcentration stage (Table 2). RDS and recovery percentage was $0.9 \%$ and 97\%, respectively (Table 2).

Table 2- The LOD, percesion and accuracy of the procedure

\begin{tabular}{ccccc}
\hline $\begin{array}{c}\text { Concentration } \\
\text { factor }\end{array}$ & $\begin{array}{c}\text { Recovery } \\
\text { percentage }\end{array}$ & RDS & $\begin{array}{c}\text { LOD for the device } \\
(\mu \mathrm{g} / \mathrm{l})\end{array}$ & LOD $(\mu \mathrm{g} / \mathrm{l})$ \\
\hline $\mathbf{8 0}$ & $\mathbf{9 7 \%}$ & $\mathbf{0 . 9 \%}$ & $\mathbf{3 6 . 8}$ & $\mathbf{0 . 4 6}$ \\
\hline
\end{tabular}

\section{DISCUSSION}

Increasing $\mathrm{pH}$ from 3 to 5 enhanced the selenium ion removal rate, an effect that was reduced at $\mathrm{pH}$ 7. The maximum selenium ion removal rate was recorded at $\mathrm{pH}$ 5. Depending on the type of adsorbent, functional groups and surface charge, $\mathrm{pH}$ can have different effects on the pattern of adsorption. Moreover, the higher adsorption of selenium in $\mathrm{pH}$ 4-6 may be due to the electrostatic interaction between the negatively charged anions and the positively charged adsorbent surface. The decrease in adsorption in higher $\mathrm{pH}$ values could be due to the abundance of $\mathrm{OH}^{-}$ions and generation of a repulsive force between the negatively charged surface and anionic molecules. In highly acidic $\mathrm{pH}$ values, the tendency for adsorption is reduced on the surface because selenium anions tend to interact with $\mathrm{H}^{+}$instead of the surface (8).

The amount of adsorbent is another important factor affecting the inhibition of metal cations and the pre-concentration process. At a constant concentration of metal ions, increasing the amount of adsorbent increases the number of adsorption sites, while at a very low amount, the adsorbent's surface becomes saturated with metal ions, resulting in the incomplete removal of metal ions from the solution (9). In this study, the complete adsorption time was 15 minutes, which can be attributed to the high level of nano-adsorbents used in the study. It is important to note that a suitable detergent should be able to wash the analyte thoroughly without damaging the adsorbent's structure (11). The selenium recovery percentage was highest when using $\mathrm{H}_{2} \mathrm{SO}_{4}$ as detergent. In concentrations less than 2 normal, the recovery percentage was low due to presence of insufficient acidic protons for replacing the selenium adsorbed onto the adsorbent's surface.

\section{CONCLUSION}

This study is the first to successfully utilize thiolated nanosilica for measuring low selenium levels. The solid phase extraction method was used to preconcentrate and determine low selenium quantities by thiolated $\mathrm{SiO}_{2}$ nanosilica absorbent and UV-visible spectrophotometry. Optimized conditions for preconcentration of a $25 \mathrm{ml} 0.2 \mathrm{mg} / \mathrm{l}$ selenium solution are $\mathrm{pH}$ of $5,40 \mathrm{mg}$ of adsorbent, sample-adsorbent mixing time of 15 minutes and $5 \mathrm{ml}$ of $2 \mathrm{~N}$ sulfuric acid as detergent. Thiolation of the adsorbent increases selenium adsorption by thiolated-silica compared to $\mathrm{SiO}_{2}$.

\section{ACKNOWLEDGEMENTS}

This project has been partly funded by a joint research grant from Golestan University of Medical Science and Gorgan University of Agricultural Sciences and Natural Resources.

\section{CONFLICT OF INTEREST}

The authors declare that there is no conflict of interest regarding publication of this article. 


\section{REFERENCES}

1. Li T, Yu L-J, Li M-T, Li W. A new approach to the standard addition method for the analysis of $F, A l$ and $K$ content in green tea. Microchimica Acta. 2006; 153(1-2): 109-14.

2. Sunde RA. Molecular biology of selenoproteins. Annu Rev Nutr. 1990; 10(1): 451-74. DOI:10.1146/annurev.nu.10.070190.002315.

3. Hamilton SJ. Review of selenium toxicity in the aquatic food chain. 2004; 326(1-3): 1-31.

4. Yang G, Zhou R. Further observations on the human maximum safe dietary selenium intake in a seleniferous area of China. J Trace Elem Electrolytes Health Dis. 1994; 8(3-4): 159-65.

5. Grant K, Goldizen FC, Sly PD, Brune M-N, Neira M, van den Berg M, et al. Health consequences of exposure to e-waste: a systematic review. 2013; 1(6): e350-e61.

6. Rahman I, Vejayakumaran P, Sipaut C, Ismail J, Bakar MA, Adnan R, et al. An optimized sol-gel synthesis of stable primary equivalent silica particles. Lancet Glob Health. 2013; 1(6): e350-61. doi: 10.1016/S2214109X(13)70101-3
7. Dalvie MA, Sinanovic E, London L, Cairncross E, Solomon A, Adam H. Cost analysis of ELISA, solidphase extraction, and solid-phase microextraction for the monitoring of pesticides in water. Environmental Research. 2005; 98(1): 143-50.

8. McKittrick MW, Jones CW. Toward single-site functional materials preparation of amine-functionalized surfaces exhibiting site-isolated behavior. Chem Mater. 2003;15(5):1132-9.

9. Sabik H, Jeannot R, Rondeau BJ. Multiresidue methods using solid-phase extraction techniques for monitoring priority pesticides, including triazines and degradation products, in ground and surface waters. $\mathrm{J}$ Chromatogr A. 2000; 885(1-2): 217-36.

10. Najafi M, Rostamian R, Rafati A. Chemically modified silica gel with thiol group as an adsorbent for retention of some toxic soft metal ions from water and industrial effluent. Chemical Engineering Journal. 2011; 168(1): 426-32.

11. Hui K, Chao CYH. Synthesis of MCM-41 from coal fly ash by a green approach: Influence of synthesis $\mathrm{pH}$. Journal of Hazardous Materials. 2006; 137(2): 11351148 